\title{
Stability analysis of power system with the penetration of photovoltaic based generation
}

\author{
Mohammed Masum Siraj Khan, Md. Shamsul Arifin, Ariful Haque, Nahid-Al-Masood \\ Department of Electrical and Electronic Engineering, Bangladesh University of Engineering and Technology, Dhaka-1000, Bangladesh
}

Email address:

moonna07buet@gmail.com (M. M. S. Khan), shamsularifin126@gmail.com (M. S. Arifin)

\section{To cite this article:}

Mohammed Masum Siraj Khan, Md. Shamsul Arifin, Ariful Haque, Nahid-Al-Masood. Stability Analysis of Power System with the Penetration of Photovoltaic Based Generation. International Journal of Energy and Power Engineering. Vol. 2, No. 2, 2013, pp. 84-89. doi: $10.11648 /$ j.ijepe.20130202.18

\begin{abstract}
As the recognition in renewable energy is increasing widely, the development of renewable energy can be major alternative energy resources in Bangladesh. This paper represents the impact of large-scale photovoltaic generation on Bangladesh power system stability. First, the model of PV based generator has been analyzed. Then system-loading margin is studied without and with PV based generator. The contribution of PV based generator on solving under voltage problem and improving bus voltage is studied in the paper. This paper will also show the solution of overloading problem of power transformers with solar PV generator. The transient voltage, angle and frequency stability with PV based generator is discussed also.
\end{abstract}

Keywords: Loadibility, Load Margin, Photovoltaic Generator, P-V Curve, Static Voltage Stability, Transient Voltage Stability

\section{Introduction}

Electricity grid in the $21^{\text {st }}$ century will be completely different from the last century. Now-a-days, the people around the world are more concern about climate change and energy security. That's why, governments of different countries around the world are considerably interested on renewable energy due to reducing energy related environmental problems, specially $\mathrm{CO}_{2}$ emission and energy security. A new large and inexhaustible source of energy that has capability to generate power requirements of the world on a contained basis is simply called "renewable energy". Among renewable energy options, wind and photovoltaic options are usual choices for having several advantages [1].

Grid connected solar photovoltaic generation can introduce several unexpected conditions to the system like voltage fluctuation in distribution feeder, high transmission and distribution losses, overloading, introducing of flicker and harmonics etc [2-3]. Photovoltaic generation has some comparative advantages over wind generation. In spite of having high initial investment, the solar PV generation becomes increasingly attractive to most developed and some of the developing countries in recent past and the total generation by photovoltaic system is increasing day by day.

According to studies done by European PV industries Association (EPIA) the faster growing PV is grid connected one rather than standalone PV system. However, two of the strongest challenges of PV generation are intermittency and power quality. These impede the widespread development of PV generation. It is usually believed that solar PV generation can have influence on system's stability. Thus, main purpose of the paper is to show the impact of PV generation in Bangladesh power with system's static and transient voltage stability for different aspects.

This paper is organized as follows. In section 2, describes the concept of oscillatory and static voltage stability. Section 3 and 4 presents the model of PV generator and Bangladesh power system along with analysis tools used in the paper. Numerical results and discussion are presented in section 5. Finally, in section 6 , a conclusion is drawn by discussing the simulation results. 


\section{Oscillatory and Static Voltage Stability}

Oscillatory stability analysis of power system deals with small disturbances and the ability of power system to maintain synchronism under such disturbances [4-6]. Typical analysis that provides valuable information about the system inherent dynamic nature is based on linearized system [7]. Linearization holds true as disturbance considered is small and sudden. Oscillatory instability problem can be global and local in nature [8].

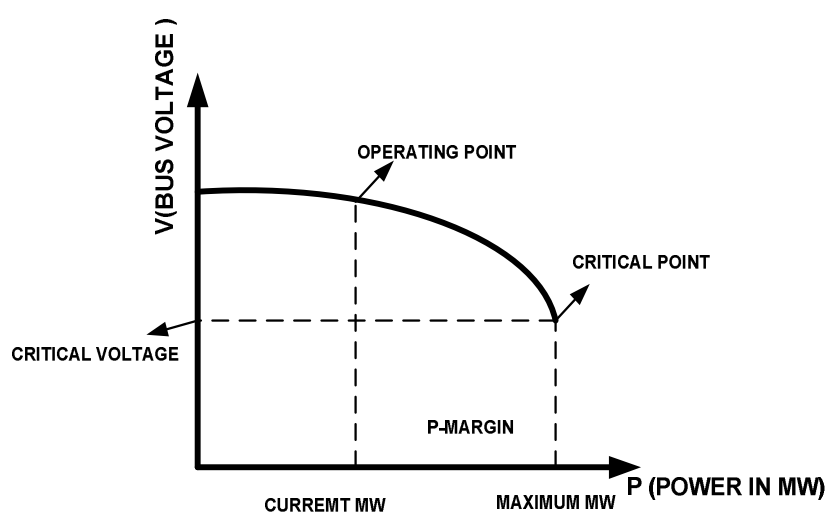

Fig 1. A typical PV curve

Static voltage instability is actually related to the reactive power imbalance. The reactive power support which the bus receives from the system, can limit loadability of that bus and hence the entire system. If the reactive power support reaches below the limit, the system will approach to maximum loading point or voltage collapse point due to high real and reactive power losses [9-11]. Hence, the reactive power supports should be local and adequate in order to avoid problem associated with its transmission [12], especially in a stressful condition. This phenomenon can be seen from the plot of the voltage at receiving end versus power transferred. The plots are popularly referred to as P-V curve or "Nose" curve. Figure 1 shows a typical $\mathrm{P}-\mathrm{V}$ curve of a synchronous generator. As the power transfer increases, the voltage at the receiving end decreases. Eventually, the critical (nose) point, the point at which system reactive power is depleted, is reached where any further increase in active power transfer will lead to very rapid decrease in voltage magnitude [13-14]. Before reaching to critical point, the large voltage drop due to heavy reactive power losses can be observed. The maximum load that can be increased prior to the point at which the system reactive power depleted is called static voltage stability margin or loading margin (LM) of the system. The only way to save the system from voltage collapse is to reduce the reactive power losses in the transmission system or to add additional reactive power prior to reaching the point of voltage collapse [15-16]. This has to be carried out in planning with several system-wide studies.

\section{Photovoltaic Generator}

Photovoltaic generator is based on semiconductor device and solid-state synchronous voltage source converter that is analogous to a synchronous machine except the rotating part. Voltage source converter in photovoltaic generator converts a DC input voltage into AC output voltage and supply active and reactive power to the system. It generates a balance set of sinusoidal voltage at fundamental frequency with rapidly controllable amplitude and phase angle. A typical grid connected photovoltaic generator is shown in figure 2.

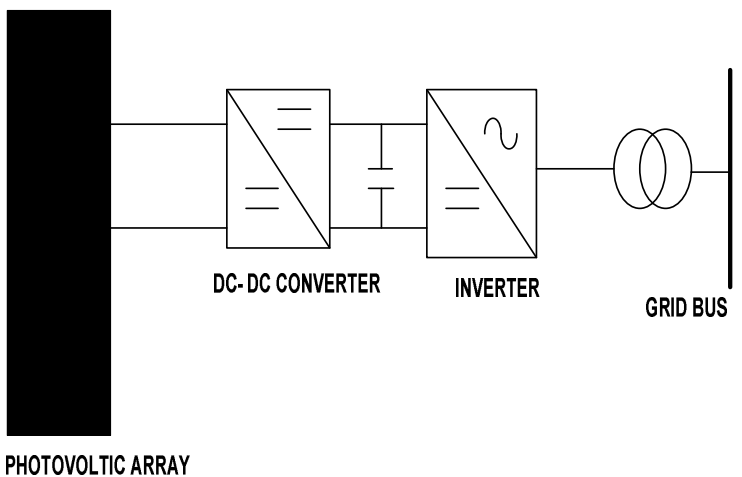

Fig 2. A typical grid connected PV generator

\section{Bangladesh Power System and Tool}

To observe the impact of PV generation at large scale on static voltage stability of a real power system, Bangladesh power system has been selected. A single line diagram of Bangladesh power system consists of 119 synchronous generators. There are total 548 buses with 2 different transmission line voltages, $132 \mathrm{KV}$ and $230 \mathrm{KV}$, respectively with totaling $5277.089 \mathrm{MW}$ and 1839.873 Mvar.

CYME PSAF 2.81 has been used for performing power flow analysis and transient stability analysis of Bangladesh power system. For observing the impact of solar PV generation in Bangladesh power system synchronous generators have been modeled as a generator, which delivers active power only. Result presented in this paper is produced by MATLAB 7.4.

\section{Simulation Results}

The continuous power flow and transient stability analysis has been performed without and with solar PV for the results below. Solar PV generator is connected at different buses of different zone.

\subsection{Improvement of Loading Margin}

Figure 3 shows the single line diagram of interconnection of components of a part of Chittagong zone, where we have placed solar PV generator of different sizes for static voltage stability study. PV generator is placed at 
COX1 bus. At first the static load at COX1 bus has been increased, keeping the load of COX 2 fixed until the critical point of operation comes. Then the static load of COX2 is varied similarly, keeping the load of COX1 fixed. Here COX1 and COX2 buses operate at $33 \mathrm{KV}$ voltages.

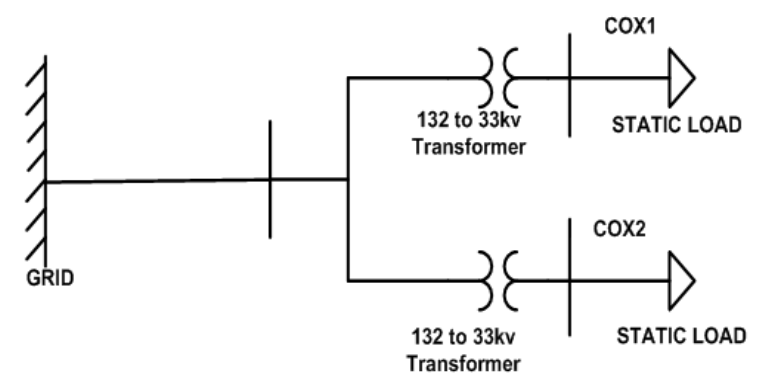

Fig 3. Single line diagram of interconnection of COX1 and COX2 bus.

Figure 4 and 5 shows the impact of connecting solar PV generator on two buses respectively. From the simulation result presented in figure 4 it is observed that the loadibility and the load margin has been improved at COX1 bus by using solar PV generator of various sizes. Figure 5 shows the improvement of load margin and loadibility of COX2 bus for using solar PV generator at COX1 bus and COX2 bus.

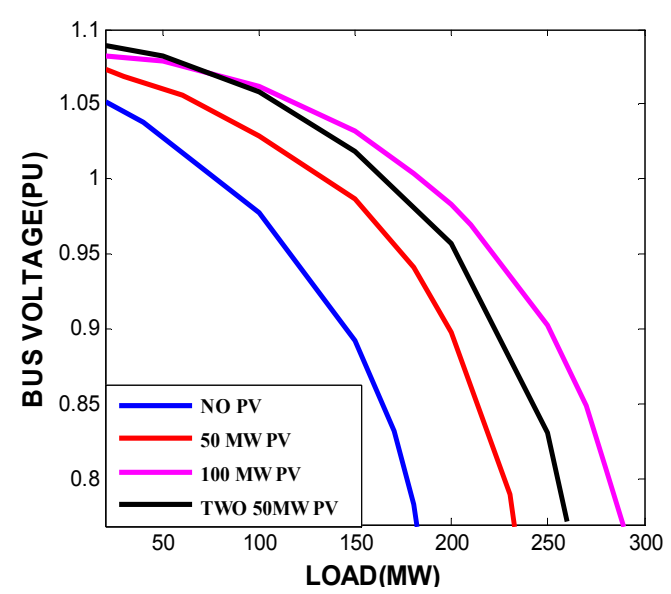

Fig 4. Effect of $P V$ generator on loading margin of COX1 bus.

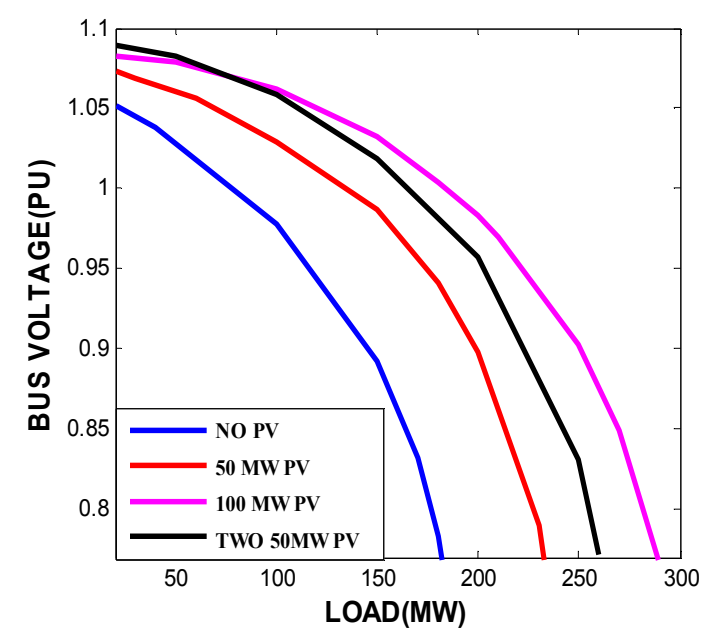

Fig 5. Effect of PV generator on loading margin of COX2 bus.
Figure 6 shows the single line diagram of another part of Chittagong zone, where we have connected solar PV generator of different sizes for observing the result. Here COMILLAN1 and COMILLAN 2 buses operate at $33 \mathrm{KV}$ voltages. PV generator of various sizes is placed at COMILLAN 1 and COMILLAN 2 buses and the impact is shown in figure 7 and figure 8 . From the simulation result presented in figure 7 it is observed that the loadibility and the load margin have been improved at COMILLAN 1 bus by using solar PV generator. Figure 8 shows the improvement of load margin and loadibility of COMILLAN 2 bus for using solar PV generator.

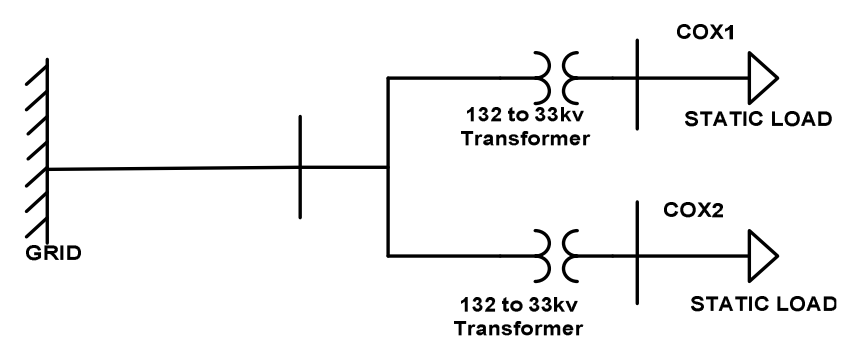

Fig 6. Single line diagram of COMILLAN 1 and COMILLAN 2 bus.

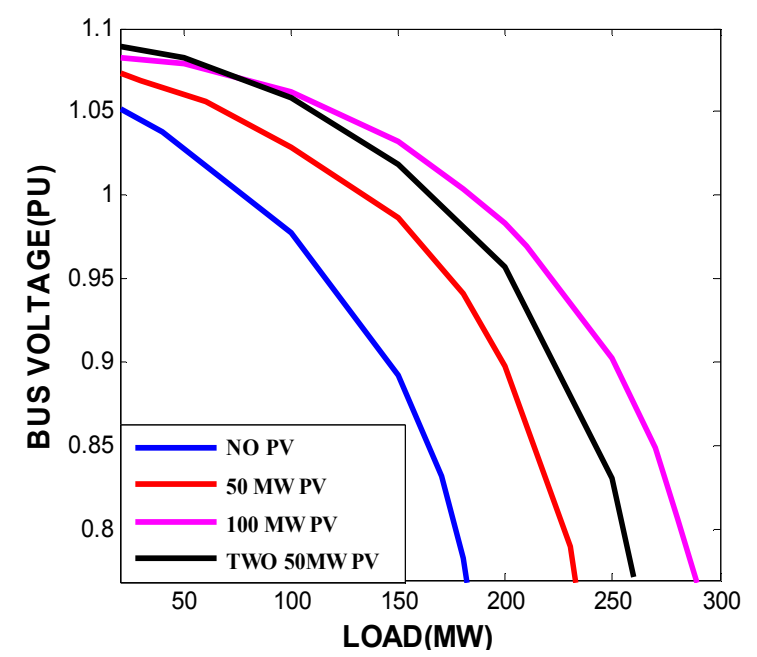

Fig 7. Effect of PV generator on loading margin of COMILLAN 1 bus

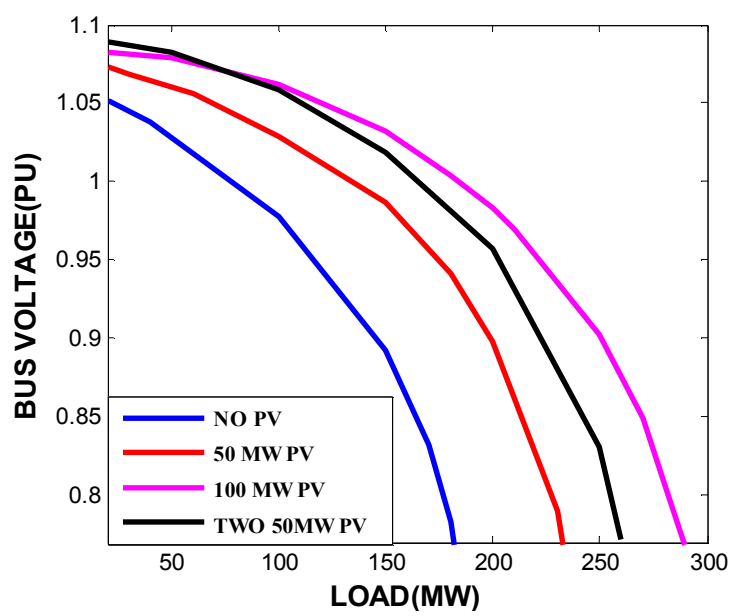

Fig 8. Effect of PV generator on loading margin of COMILLAN 2 bus 


\subsection{Improvement of Bus-Voltage}

Figure 9 shows the single line diagram of a part of Dhaka zone, where solar PV generator is placed to study the solution of under voltage problem. Here JAMALPUR1, JAMALPUR2 and JAMALPUR3 buses operate at $33 \mathrm{KV}$ voltages. Figure 10 shows the impact of connecting solar PV generator at JAMALPUR2 bus, which has under voltage problem. The under voltage problem has been solved by connecting a solar PV at that bus. Moreover the voltage of its nearest buses JAMALPUR1and JAMALPUR3 has also been improved due to solar PV at JAMALPUR2 bus.

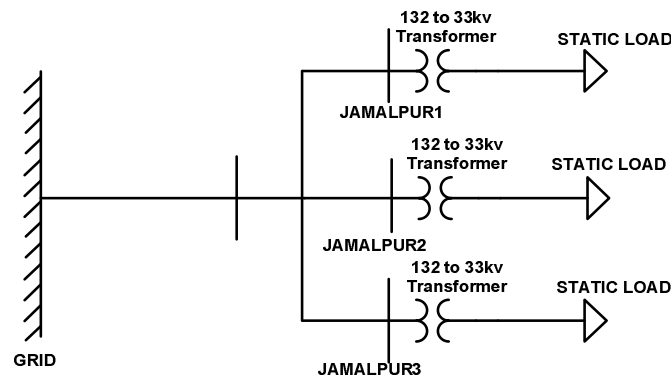

Fig 9. Single line diagram of 3 buses at Dhaka zone.

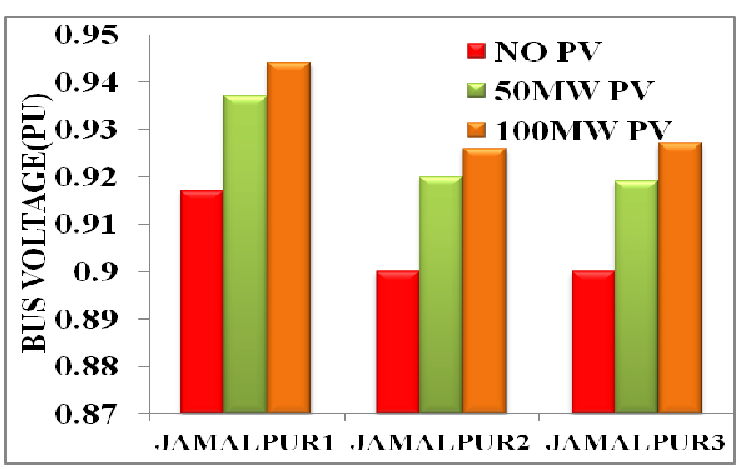

Fig 10. Effect of PV generator on improvement of bus voltage.

\subsection{Solution to Overloading Problem of Transformer}

Table I shows the specifications and positions of some overloaded transformers. Solar PV generator is connected to the secondary of the transformers to solve overloading problem. Figure 11 shows the result of connecting solar PV to the load sides of the transformers. From the figure we observe that at first percent loading has decreased with the increase of solar generation until it reaches to a minimum value. After crossing the value percent loading has increased with the increase of solar generation. At first case solar PV supplies active power locally to the load. So power need not flow from the grid through transformer. For this loading has decreased with the increase of solar generation. But if solar generation has been increased largely, after meeting local demand the residual power flows to the grid at opposite direction through transformer. For this loading has increased with the increase of solar generation.

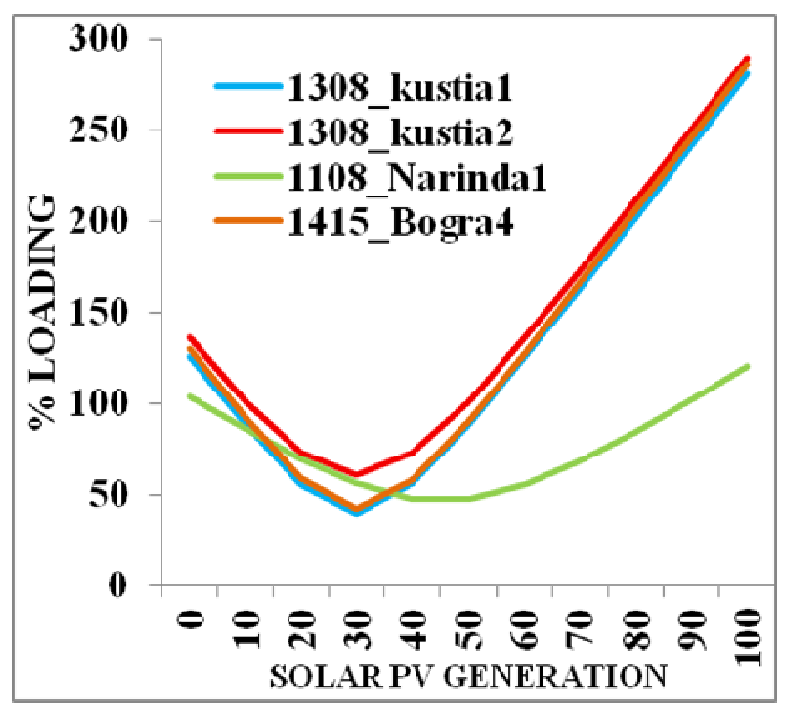

Fig 11. Effect of PV generator on overloaded transformers.

Table I. Transformers overloading problem solution with PV generation

\begin{tabular}{|c|c|c|c|c|}
\hline Transformer Name & Primary connected to bus & Secondary connected to bus & $\begin{array}{c}\text { Specification } \\
\text { (Primary to Secondary voltage) }\end{array}$ & $\begin{array}{l}\text { Rating } \\
\text { (MVA) }\end{array}$ \\
\hline 1308_Kustial & 1308 & Kustial & 132to $32 \mathrm{kv}$ & 25 \\
\hline 1308_Kustia2 & 1308 & Kustia1 & 132 to $32 \mathrm{kv}$ & 25 \\
\hline 1108_Narinda1 & 1108 & Narinda1 & 132 to $32 \mathrm{kv}$ & 25 \\
\hline 1415_Bogra4 & 1415 & Bogra4 & 132 to $32 \mathrm{kv}$ & 25 \\
\hline
\end{tabular}

\subsection{Transient Stability}

Figure 12 shows the transient voltage stability of Chittagong zone at COMILLAN1 bus after adding $40 \mathrm{MW}$ load while $100 \mathrm{MW}$ solar PV is connected to that bus. From the figure we observe that although there is a very few fluctuation of voltage magnitude after the load modification, it will not at all harmful for total system stability. Figure 13 and 14 shows the transient angle and frequency stability of same bus at same condition, which is completely satisfactory. Similarly figure 15 show the transient voltage stability of COMILLAN1 bus after cutting $20 \mathrm{MW}$ load while $100 \mathrm{MW}$ solar PV is connected to that bus and figure 16 and 17 show the transient angle and frequency stability of same bus at same condition. From these figures it is clear that after adding PV generator in Bangladesh power system in Chittagong zone at COMILLAN1 bus no major changes happened in Bangladesh power system. 


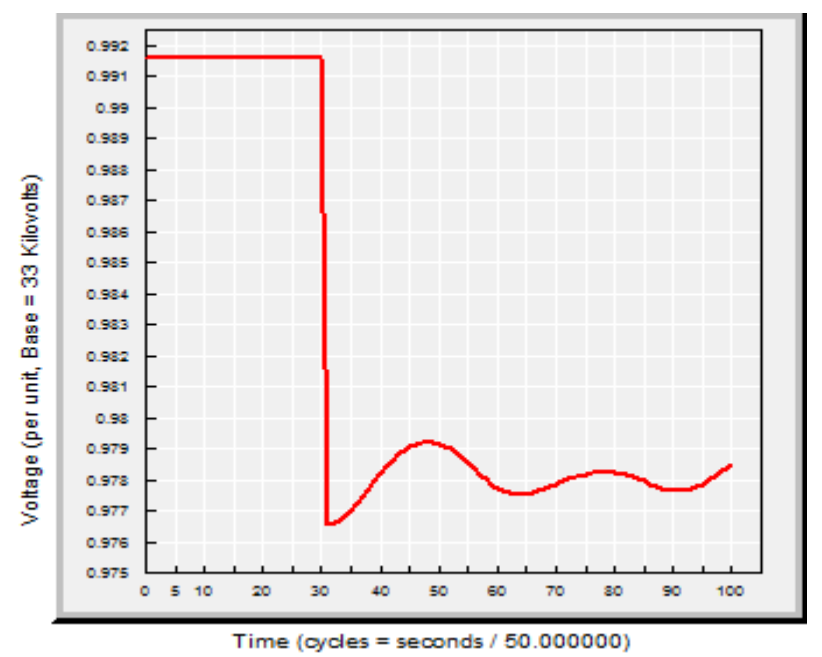

Fig 12. Effect of $P V$ generation on transient voltage stability (with addition of new loads).

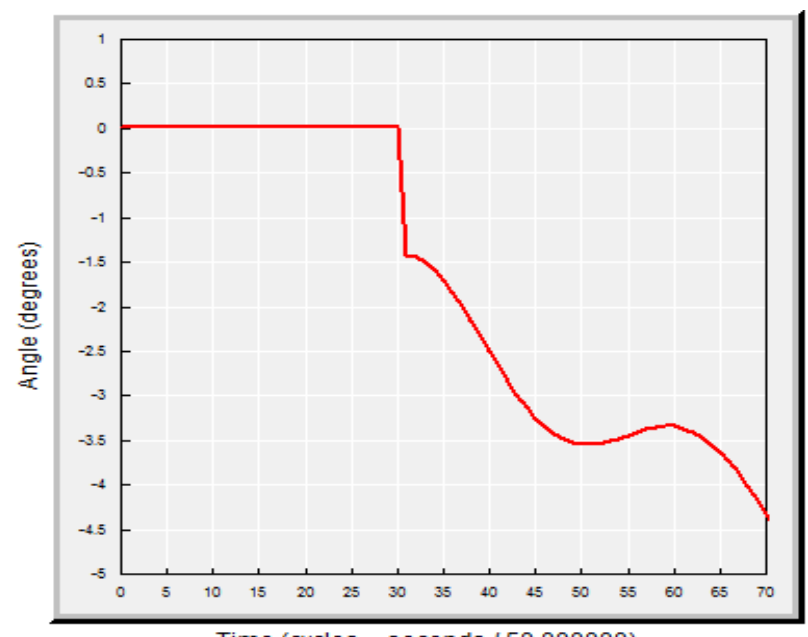

Fig 13. Effect of PV generation on transient angle stability (with addition of new loads).

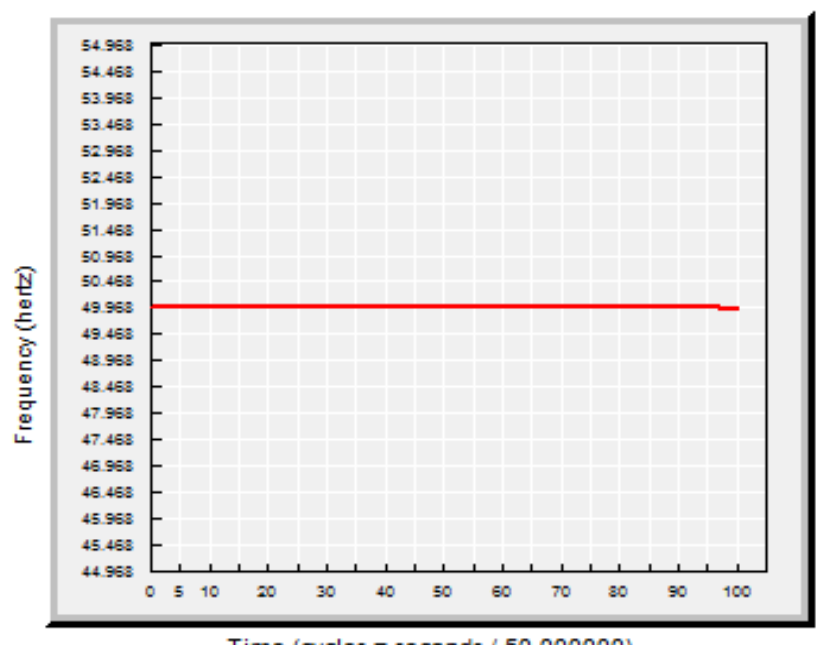

Fig 14. Effect of $P V$ generation on transient frequency stability (with addition of new loads).

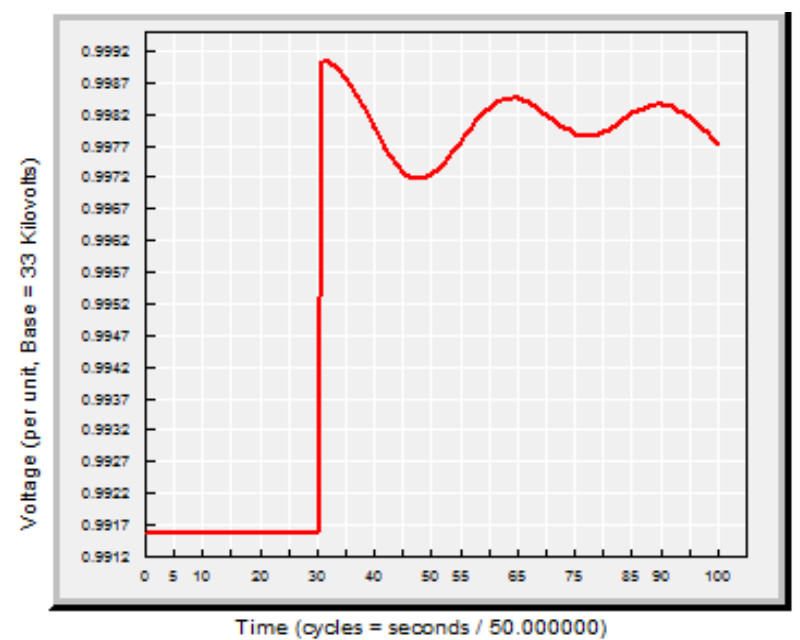

Fig 15. Effect of $P V$ generation on transient voltage stability (with rejection of loads).

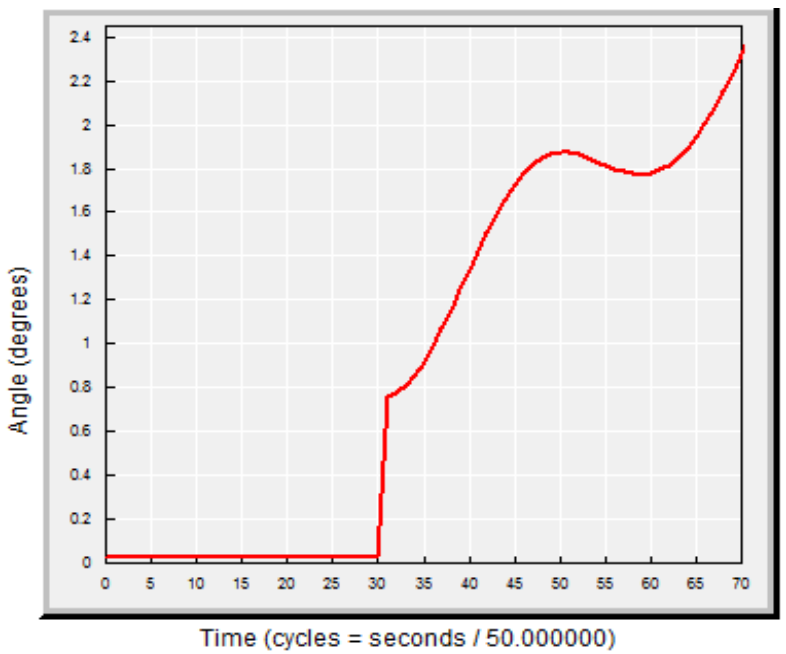

Fig 16. Effect of $P V$ generation on transient angle stability (with rejection of loads).

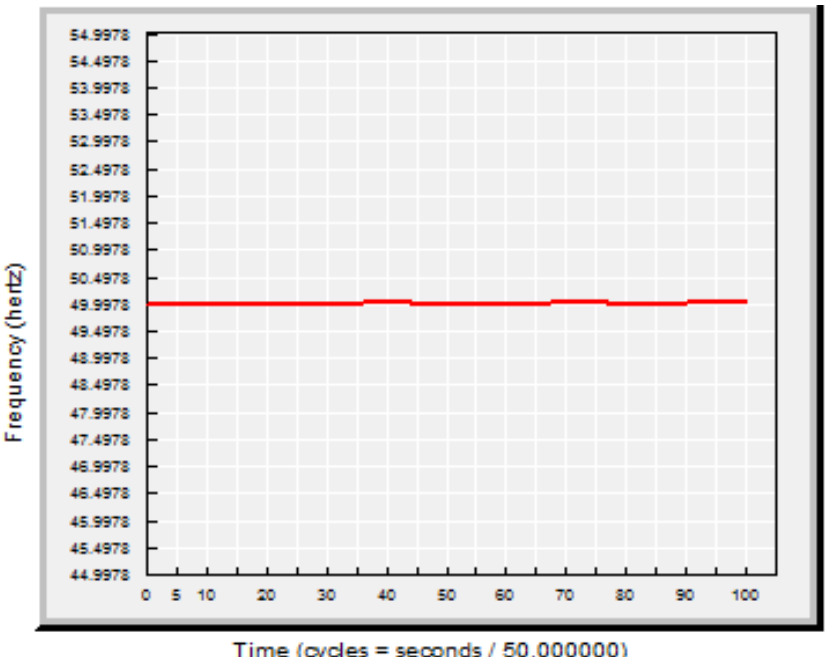

Fig 17. Effect of PV generation on transient frequency stability (with rejection of loads). 


\section{Conclusion}

Power system stability is defined as an ability of the power system to reestablish the initial steady state or come into the new steady state after any variation of the system's operation value or after system's breakdown. The stability and reliability of the electric power system is highly actual topic nowadays.

The paper has shown the impact of PV generation on Bangladesh power system stability. In medium size power systems like Bangladesh, PV generation have strong characteristics to improve the system's stability. Simulation results of static voltage stability in Bangladesh power system show solar PV generator of different sizes at different zones has improved the voltage collapse point near the bus and loading margin. Moreover, the transient voltage, angle and frequency after load modification are also satisfactory under solar connected condition.

Under voltage at different buses is one of the most discussed problems that exists almost all power systems. Under voltage is the sign of poor power quality. The under voltage problem can be solved by a solar PV generator.

However, for a power system overloading of transformer is another common problem. Due to overloading the transformer becomes overheated, hence causes damage to it. Using solar PV generator can be an effective solution of this problem. However, to solve the overloading problem of the transformer and to utilize the transformer efficiently, the size of solar generator must be selected within a definite range. Otherwise, the overloading problem may be rather more severe for using solar PV generator. However it is to be noted that not only the solar connecting buses, but also its nearest buses have get advantages from that PV generator.

Transient stability denotes how fast a power system can reach to its stable condition. This paper deals with the potential of the evaluation in term of transient stability of the electric power system. This paper discusses transient stability of power system with the addition and rejection of load to a power system in terms of transient voltage, angle and frequency stability when solar PV generation is connected to power system. These discussions represent that connecting PV generation to a power system will improve the transient stability and make a power system more stable.

Conclusion that can be drawn from the study is that, interconnection of PV based generator to the Bangladesh power system will make the system more strong against instability problem and some other common problems.

\section{References}

[1] Mukund R. Patel, Wind and Solar Power Systems, CRC press, 1999.

[2] Carson W.Taylor, Power System Voltage Stability, The EPRI Power System Engineering Seris, McGraw-Hill, Inc.

[3] M. Klein, G. J. Rogers, P. Kundur, A fundamental study of inter-area oscillations in power systems, IEEE Trans. Power Syst. 6 (1991) 914-921.

[4] P.Kunder, Power System Stability and Control, McGrawHill, Inc, 1994.

[5] Tang Hong, WuJunling, Zhou Shuangxi, Modeling and Simulation for Small Signal Stability Analysis of Power System Containing Wind Farm, J. Power Syst. Techno. 28 (2004) 38-41.

[6] IEEE/CIGRE joint task force on stability terms and definitions, Definition and classification of power system stability, IEEE Trans. Power Syst. 19 (2004) 1387-1401.

[7] John J. Grainger, William D. Stevenson, Jr, Power System Analysis, McGraw-Hill, Inc, 1994.

[8] C.A Canizares, N. Mithulan, and , J Reeve, Linear performance indices to predict oscillatory stability problems in power systems, IEEE Trans. Power Syst. 19 (2004) 11041114.

[9] A.Sode -Yome, N. Mithulan and K.Y.Lee, A Maximum Loading Margin Method for Static Voltage Stability in Power Systems, IEEE Trans. Power Syst. 21 (2006) 799808.

[10] S.-Y. Ruan, G.-J.Li, B.-T.Ooi and Y.-Z.Sun, Power system damping from real and reactive power modulations of voltage source converter station, IET Genera, Transmi. \& Distri. Jour. 2 ( 2008) 3311-320.

[11] N. A. Ahmed and M. Miyatake, A novel maximum power point tracking for photovoltaic application under partially shaded insolation conditions, Elect. Power Syst. Res. $8(2008)$ 777-784.

[12] Frede Blaabjerj, Zhe Chen and Soeren Baekhoej Kiaer, Power Electronics as Efficient Interface in Dispersed Power Generation Systems, IEEE Trans. Power Electron. 19. (2004) 1186-1194.

[13] Y. Halevi and D. Kottick , Optimization of load shedding system, IEEE Trans. Energy Convers. 8 (1993) 207 -213.

[14] I. Song, M. Kim, and M. Youn, New maximum power point tracker using sliding-mode observer for estimation of solar array current in the grid-connected photovoltaic system, IEEE Trans. Ind. Electron. 53 (2006) 1027-1035.

[15] F. Milano, An open source power system analysis toolbox, IEEE Trans. Power Syst. 20 (2005) 1199 - 1206.

[16] Canizares and Z.T Faur, Analysis of SVC and TCSC controllers in Voltage collapse, IEEE Trans. Power Syst. 14 (1999) 158-165. 